\title{
Article \\ Students' Depression and School Burnout in the Context of Family Network Acceptance and Deviation from Balanced Time Perspective
}

\author{
Emilia Macałka ${ }^{1}$, Katarzyna Tomaszek ${ }^{2}$ (D) and Joanna Kossewska ${ }^{3, *(D)}$ \\ 1 Rehabilitation and Educational Center, 32-340 Wolbrom, Poland; macalka.emilia@gmail.com \\ 2 Institute of Psychology, Pedagogical University of Kraków, 30-084 Kraków, Poland; \\ katarzyna.tomaszek@up.krakow.pl \\ 3 Institute of Special Education, School Education and Teachers Education, Pedagogical University of Krakow, \\ 30-084 Kraków, Poland \\ * Correspondence: joanna.kossewska@up.krakow.pl
}

check for updates

Citation: Macałka, E.; Tomaszek, K.; Kossewska, J. Students' Depression and School Burnout in the Context of Family Network Acceptance and Deviation from Balanced Time Perspective. Educ. Sci. 2022, 12, 157. https://doi.org/10.3390/educsci12030157 Academic Editor: Eila Jeronen

Received: 4 December 2021 Accepted: 14 February 2022 Published: 24 February 2022

Publisher's Note: MDPI stays neutral with regard to jurisdictional claims in published maps and institutional affiliations.

Copyright: (C) 2022 by the authors. Licensee MDPI, Basel, Switzerland. This article is an open access article distributed under the terms and conditions of the Creative Commons Attribution (CC BY) license (https:// creativecommons.org/licenses/by/ $4.0 /)$.

\begin{abstract}
Nowadays, a growing increase in depression and school burnout is being observed in students. The research aim is to test the mediating effect deviation from balanced time perspective, gender, and subjective sense of family network acceptance on the relationship between depression and school burnout. The sample consisted of 355 students ( $61.6 \%$ girls, $48.4 \%$ boys) from the third grade of high school in the south of Poland (mean age 18.5). The student school burnout scale for youth, Time Perspective Inventory, and Depression Scale for youth were used in the survey. Results showed significant relationships between the time perspective indicators, depression, and school burnout as well as a mediation effect of the past time perspective and the fatalistic present time perspective towards depression through school burnout. The findings confirmed that the focus of a person on immediate hedonistic goals becomes significant for the severity of depression only after accounting for the level of school burnout. Conclusions comprised the design of psychological interventions aimed at the group of young people experiencing depression and school burnout considering the time perspective development.
\end{abstract}

Keywords: depression; school burnout; deviation from balanced time perspective; adolescence; family network

\section{Introduction}

Nowadays, adolescents experience many difficulties in the course of normative development, the accumulation of which can lead to mental disorders [1]. In particular, depressive symptoms are observed very often in adolescence and can be the cause of poor academic performance [2], e.g., when school environments make students feel pressured [3] and when students cannot meet educational expectations or perceive a discrepancy between their individual resources (internal and/or external) and their personal expectations of school success. Due to such experiences, school burnout arises with three dimensions: emotional exhaustion, cynicism towards school, and a sense of inadequacy as a student. Although the concept of burnout was firstly proposed in [4] and is usually addressed as a workplace-related syndrome followed by Maslach theory [5], it has also been studied in the school context [6-8]. In turn, this is followed by many negative short- and long-term psychosocial consequences [9-11].

A good defense against depression is a balanced time perspective (BTP), which is optimal for the mental well-being of an individual [12]. The concept was developed within the Time Perspective Theory by Zimbardo and Boyd [13]. Human life takes place within the time dimension and human actions are always in relation to the past, present, or future; so, experiencing the temporal context is an extremely important factor in normative 
development. Time perspective affects both cognitive and affective human functioning and is generally defined as an unconscious process of organizing personal experiences on a timeline so that they can be given sequence, coherence, and meaning. Zimbardo and Boyd $[13,14]$ distinguished five time perspectives: Past-Negative, Past-Positive, PresentHedonistic, Present-Fatalistic, and Future. A tendency to focus on particular time perspectives, especially Past-Negative and Present-Fatalistic, might be predictive of a higher level of depressive symptoms, whereas Past-Positive appears to protect individuals from elevated levels of depressive symptoms $[13,15]$. In general, people rating high on PastPositive and Present-Hedonistic time perspectives also exhibit increased well-being and life satisfaction [16,17]; additionally, they are happier, in contrast with those scoring higher in the Past-Negative time perspective who experienced less happiness [18]. Compared with other time perspectives, Present-Hedonistic $(\mathrm{PH})$ was the most robust predictor of current emotional states. Hedonism, from which the name for the $\mathrm{PH}$ is taken, is defined as openness to pleasurable experience [19] and is associated with lower levels of depressive symptoms [20] and lower academic performance [21].

Developing a balanced time perspective (BTP) is optimal for the mental well-being of an individual. It is characterized by being rooted in positive experiences and memories from the past (past-positive temporal perspective) with no tendency to remember negative past events (past-negative temporal perspective), a balanced tendency to engage in behaviors motivated by hedonistic pleasure (present-hedonistic temporal perspective), a weak tendency to perceive current experiences in minor key tones (present-fatalistic temporal perspective) as well as a strong motivation to build rational plans for the future (future temporal perspective). The occurrence of the deviation from a balanced time perspective (DBTP) may lead to the appearance of problems in the functioning of the individual and a higher incidence of depression [12].

The subjective perception of social support seems to be an important factor differentiating the level of depression, school burnout, and negative time perspective. Research has shown that, on the one hand, social support from family, friends, and immediate community has a positive effect on mental health among adolescents [22]; contrarily, a lack of social support is followed by mental health problems, including the severity of depression symptoms, and has a negative impact on the perceived level of quality of life by students [23].

A sense of security and acceptance is key in shaping the future time perspective [24]. In a secure relationship, parents allow their child to explore the space in the time context and plan their achievements. Growing up in a well-functioning family seems to be the core element for the development of a positive past perspective, due to recalling many good moments from childhood $[13,14]$. Proper family relationships protect students against appearance of the exhaustion syndrome and social support helps to cope with stress related to fulfilling academic duties [25]. Peer support affects the psychological well-being of students and their academic performance [26] but students assessing the quality of family relationships as worse experience significantly higher levels of school burnout [27].

Since burnout generally emerges in a period of youth that is particularly sensitive to the onset of depressive symptoms, scholars have been led to consider depression and burnout as two overlapping dimensions co-occurring in students. Indeed, longitudinal as well as cross-sectional studies have supported the role of students' school burnout in predicting their later depressive symptoms development [28,29]. Considering positive relationships between student burnout and higher deviations from a Balanced Time Perspective (DBTP) [30], and due to the fact that family conditions might be found as negative antecedents for school burnout and depression, the current research was conducted.

The purpose of the current study was to test the mediating role of deviation from balanced time perspective (DBTP) and the moderation effect of gender and subjective sense of family acceptance on the relationships between student school burnout and depression (see Figure 1). As indicated in the introduction, the relations between time perspective and depression, as well as between student burnout and depression, are well proven; so far, 
few studies of deviation from balanced time perspective have focused on its meaning in the academic field (for a review, see [31]). No studies have examined the role of DBTP in the relationship between student burnout and depressive symptoms. Therefore, six specific hypotheses (H1-H6) are formulated:

H1. Female students score higher than boys on student burnout, depression, and DBTP.

H2. Students who experienced lower family network acceptance compared with students who experienced higher family network acceptance experienced a higher level of student burnout, depression, and DBTP.

H3. Deviation from the balanced time perspective, school burnout, and depression are positively correlated variables.

H4. Higher levels of depression are predicted by higher DBTP, which is associated with student burnout, female gender, and a lower subjective sense of family network acceptance.

H5. The relationship between student burnout and depression is mediated by DBTP.

H6. Gender and a subjective sense of family network acceptance moderate the association between student burnout and depression and between DBTP and depression.

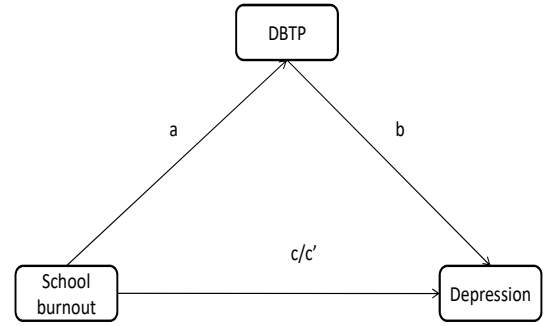

MODEL 1

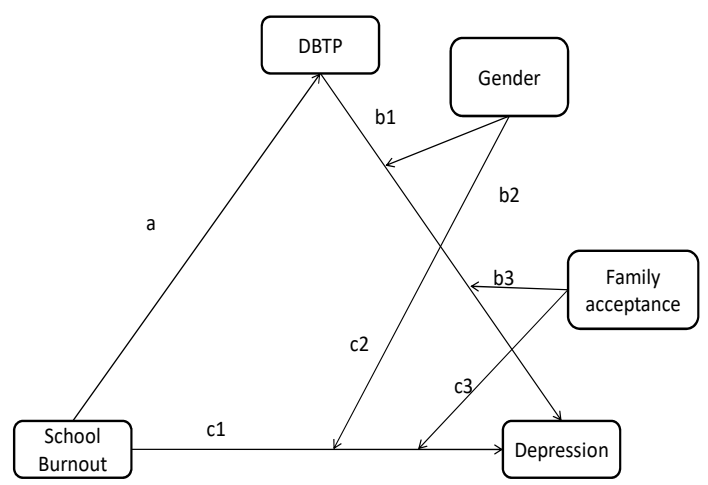

MODEL 2

(a)

(b)

Figure 1. Graphical visualization of the tested models: (a) simple mediation, (b) moderationmediation effect. Note: $\mathrm{a}$-independent variable $\rightarrow$ mediator path; $\mathrm{b}$-mediator $\rightarrow$ dependent variable path; c-direct effect, c' —-total effect.

\section{Materials and Methods}

\subsection{Study Sample}

The study was conducted in 2019 with a group of secondary school students $(N=355$; aged 18-19) in the third (final) grade who attended five randomly selected high schools located in different towns in the south of Poland. The sample consisted of 140 men (39\%) and 215 women $(61 \%)$. The respondents' specializations were as follows: $31 \%$ specialized in humanities, $60 \%$ in science, and $9 \%$ in biology/chemistry. Most of the participants lived in villages $(62 \%)$, and $38 \%$ came from cities with up to 100,000 inhabitants. Of the respondents, $83 \%$ had siblings and $17 \%$ did not. Most students lived with both parents $(83 \%)$, and $17 \%$ came from divorced parents. Having a best friend in whom a student could confide was reported by $94 \%$ of respondents; however, $6 \%$ did not have a friend or loved one that they could always rely on. A high level of subjective sense of security and family network acceptance was declared by $51 \%$ of respondents, while $49 \%$ reported a low level in this aspect. High family economic status was assessed by $77 \%$ of respondents, while $23 \%$ stated that it was poor. The survey was conducted on school premises after receiving the headmaster's permission. The participants filled in voluntary and anonymous 
questionnaires during one meeting in their free time after classes. All participants were of legal age; therefore, parental agreement was unnecessary.

\subsection{Instruments}

Tomaszek and Muchacka-Cymerman's [32] Polish adaptation of Aypay's [33] Secondary Burnout Scale (SSBS) was used. The SSBS consists of 34 questions, with a 4-point Likert scale answer (from 1-strongly agree, to 4-strongly disagree). The scale gives the student burnout total score and its seven dimensions; reliability is calculated as Cronbach's $\alpha$ : 0.83 (BFS—Burnout from Studying), 0.82 (BFF-Burnout from Family), 0.86 (LIS_Loss of Interest in School), 0.67 (BFH-Burnout from Homework), 0.75 (BFTA-Burnout from Teacher Attitudes), 0.72 (NRTF-Need to Rest and Time for Fun), and 0.72 (FIS-Feeling of Insufficiency at School).

Mojs and colleagues' [34] Polish adaptation of the shortened version of the Kutcher Depression Scale for Youth (KADS) was used. On a 3-point Likert scale (from 0-hardly ever, to 3-all of the time), respondents evaluated six items related to the following symptoms: feelings of sadness, lack of self-confidence, feelings of physical exhaustion, beliefs that life is difficult and exhausting, feelings of fear and anxiety, and emerging suicidal thoughts and plans. The reliability of the Polish scale, calculated with Cronbach's $\alpha$ coefficient, is 0.82. The original version of KADS is widely used in North America as a screening test for depression in adolescents [34].

Przepiórka's Polish adaptation of the Zimbardo Time Perspective Inventory [35] was used. It contains 56 statements, which respondents evaluated on a 5-point Likert scale assigned to five subscales: Past-Positive Temporal Perspective (PP), Past-Negative Temporal Perspective (PN), Present-Fatalist Temporal Perspective (PF), Present-Hedonistic Temporal Perspective $(\mathrm{PH})$, and Future Time Perspective $(\mathrm{F})$. The Cronbach's $\alpha$ reliability coefficients for the individual subscales in the Polish version are $0.80(\mathrm{~F}), 0.72(\mathrm{PF}), 0.72(\mathrm{PH}), 0.61(\mathrm{PP})$, and $0.85(\mathrm{PN})$.

Measurement of the deviation from the balanced time perspective (DBTP) was performed on the basis of Stolarski and colleagues [16]; it was calculated for every single individual as the Euclidean distance between the ideal (i) and empirical (e) levels of the time perspective:

$$
D B T P=\sqrt{(i P N-e P N)^{2}+(i P P-e P P)^{2}+(i P F-e P F)^{2}+(i P H-e P H)^{2}+(i F-e F)^{2}}
$$

\subsection{Statistical Data Analysis}

Statistica 13.3 and IBM SPSS Statistics version 22 with the macros presented by Hayes [36] were used for statistical data analyses. First, the study sample was divided into two subgroups according to sex and family network acceptance; then, the level of the dependent variables was compared in these subgroups using the $t$-student coefficient. Second, Pearson's analyses were computed to identify statistically significant relationships between the tested variables. Linear Regression Analysis was conducted to assess whether DBPT, SSBS, gender, and family network acceptance were associated with adolescent depression. By calculating interaction effects with the bootstrap method, we tested the moderation effects of gender and family network acceptance on (1) the relationship between DBPT and depression and (2) the relationship between SSBS and depression. Finally, the Hayes [36] macro, the simple mediation model (Model 4), and the moderation-mediation model (Model 17) were used to examine whether the indirect (mediated) effect of school burnout in relation to depression (separate analyses) through DBPT is significant. Similarly, we tested the moderation role of gender and family network acceptance on the association between SSBS and depression and between DBPT and depression. 


\section{Results}

\subsection{Preliminary Analyses}

The descriptive statistics (mean, SD) and the basic Pearson's correlations of all the variables are presented in Tables 1 and 2 . To identify gender and family network acceptance differences in the tested variables, a student's $t$-test was conducted. The findings indicated only one significant gender difference: girls scored higher on depression than boys $\left(t_{(353)}=-2.85, p=0.005\right)$. The effect size measured by Cohen's $d$ was weak $(d=0.32)$. Positive correlations between deviation from the balanced time perspective (DBTP), school burnout (SSBS), and depression (DEP) were found in both gender subgroups; however, the relationship between DBPT and SSBS in the male sample was insignificant (see Table 1).

Table 1. Descriptive statistics and Pearson's correlations for the boys and girls samples.

\begin{tabular}{|c|c|c|c|c|c|c|c|c|c|c|}
\hline \multirow[t]{2}{*}{ Variables } & \multicolumn{2}{|c|}{$\begin{array}{c}\text { Boys } \\
(\mathrm{n}=140)\end{array}$} & \multicolumn{2}{|c|}{$\begin{array}{c}\text { Girls } \\
(n=215)\end{array}$} & \multirow[t]{2}{*}{$t_{(353)}$} & \multirow[t]{2}{*}{$p$} & \multirow{2}{*}{ Cohen's d } & \multirow[t]{2}{*}{1} & \multirow[t]{2}{*}{2} & \multirow[t]{2}{*}{3} \\
\hline & $\mathbf{M}$ & SD & $\mathbf{M}$ & SD & & & & & & \\
\hline 1. DBTP & 2.94 & 0.62 & 2.91 & 0.71 & 0.40 & 0.693 & - & - & $0.27^{* *}(\mathrm{~b})$ & $0.47^{* * *}(\mathrm{~b})$ \\
\hline 2. SSBS & 87.79 & 12.80 & 87.01 & 13.16 & 0.55 & 0.580 & - & $0.45^{* * *}$ (a) & - & 0.05 (b) \\
\hline 3. DEP & 4.36 & 3.85 & 5.65 & 4.33 & -2.85 & 0.005 & 0.32 & $0.49^{* * *}$ (a) & $0.40^{* * *}$ (a) & - \\
\hline
\end{tabular}

Note: DBTP—Deviation from balanced time perspective; SSBS—student school burnout; DEP-Depression; (a)—correlation coefficients for girls; (b) —correlation coefficients for boys; ${ }^{* * *} p<0.0001 ;{ }^{* *} p<0.001$.

Table 2. Descriptive statistics and Pearson's correlations for low and high family network acceptance subgroups.

\begin{tabular}{|c|c|c|c|c|c|c|c|c|c|c|}
\hline \multirow[t]{2}{*}{ Variables } & \multicolumn{2}{|c|}{$\begin{array}{c}\text { Low Family } \\
\text { Network } \\
\text { Acceptance } \\
(\mathbf{n}=\mathbf{1 7 1})\end{array}$} & \multicolumn{2}{|c|}{$\begin{array}{c}\text { High Family } \\
\text { Network } \\
\text { Acceptance } \\
(\mathbf{n}=\mathbf{1 8 4})\end{array}$} & \multirow[t]{2}{*}{$t_{(353)}$} & \multirow[t]{2}{*}{$p$} & \multirow[t]{2}{*}{ Cohen's $d$} & \multirow[t]{2}{*}{1} & \multirow[t]{2}{*}{2} & \multirow[t]{2}{*}{3} \\
\hline & $\mathbf{M}$ & SD & $\mathbf{M}$ & SD & & & & & & \\
\hline 1. DBTP & 3.11 & 0.65 & 2.75 & 0.66 & 5.29 & $<0.0001$ & 0.55 & - & $0.34^{* * *}(b)$ & $0.46^{* * *}(\mathrm{~b})$ \\
\hline 2. SSBS & 89.61 & 12.25 & 85.19 & 13.35 & 3.25 & 0.001 & 0.35 & $0.38^{* * *}$ (a) & - & $0.35^{* * *}(\mathrm{~b})$ \\
\hline 3. DEP & 6.37 & 4.16 & 4.00 & 3.90 & 5.54 & $<0.0001$ & 0.59 & $0.41^{* * *}$ (a) & 0.11 (a) & - \\
\hline
\end{tabular}

Note: DBTP-Deviation from balanced time perspective; SSBS-student school burnout; DEP-Depression; (a) - correlation coefficients for low family network acceptance group; (b) - correlation coefficients for high family network acceptance group; ${ }^{* * *} p<0.001$.

Deviation from balanced time perspective (DPBT), school burnout (SSBS), and depression (DEP) significantly differed between subgroups with a high vs. low level of family network acceptance, as indicated in Table 2. Students with low family network acceptance scored significantly higher on DBPT than students with high family network acceptance $\left(t_{(353)}=5.29 ; p<0.001\right.$, with a moderate effect size, $\left.\mathrm{d}=0.55\right)$, SSBS $\left(t_{(353)}=3.25 ; p=0.001\right.$, with a weak effect size, $\mathrm{d}=0.55)$, and $\mathrm{DEP}\left(t_{(353)}=5.54 ; p<0.001\right.$, with a moderate effect size, $d=0.59$ ). Regardless of the group, all tested variables were positively associated with each other, but in students with low family network acceptance, the correlation between SSBS and DEP was insignificant (see Table 2).

\subsection{Predictors of Depression}

The results of the linear regression analysis showed that three significant predictors explained $28 \%$ of the variance in depression $\left(\mathrm{F}_{(350)}=35.61 ; p<0.001 ; \Delta R^{2}=0.28\right)$ : gender $(\beta=0.17, t=3.80, p<0.001$; girls were found to be more prone to depression), family network acceptance $(\beta=-0.17, t=-3.62, p<0.001$; low family network acceptance was found to be a risk factor for depression), and DBTP $(\beta=0.40, t=8.00, p<0.001$, higher deviation from balanced time perspective predicted higher depression). The regression coefficient for SSBS was insignificant (see Table 3). 
Table 3. Student school burnout, DBTP, gender, and family network acceptance as predictors of depression-the result of linear regression.

\begin{tabular}{|c|c|c|c|c|c|c|c|}
\hline \multirow{2}{*}{ Variables } & \multirow{2}{*}{ Beta } & \multirow{2}{*}{$S E$} & \multirow{2}{*}{$\beta$} & \multirow{2}{*}{$t$} & \multirow{2}{*}{$p$} & \multicolumn{2}{|c|}{$95 \% C I$} \\
\hline & & & & & & $L L$ & $U L$ \\
\hline Gender & 1.47 & 0.38 & 0.17 & 3.80 & $<0.001$ & 0.67 & 2.18 \\
\hline Family network acceptance & -0.71 & 0.39 & -0.17 & -3.62 & $<0.001$ & -1.10 & -0.33 \\
\hline Student school burnout & 0.03 & 0.02 & 0.09 & 1.89 & 0.071 & -0.002 & 0.06 \\
\hline DBTP & 2.49 & 0.34 & 0.40 & 8.00 & $<0.001$ & 1.88 & 2.23 \\
\hline Statistics for regression model & $F_{(350)}=35.61$ & $p<0.0001$ & $R=0.54$ & $R^{2}=0.29$ & $\Delta R^{2}=0.28$ & & \\
\hline
\end{tabular}

Note: DBTP-Deviation from balanced time perspective; Beta-Unstandardized regression coefficient; SE-standard error; $\beta$-Standardized regression coefficient; $t$ - $t$ statistic; $p$ —significance; $95 \%$ CI-95\% Confidence intervals; $L L$-lower limit; $U L$ - upper limit; $R^{2}-R$-squared; $\Delta R^{2}$-corrected R-squared.

3.3. Depression as a Function of the Interactions between Independent Variables (Student Burnout, Deviation from Balanced Time Perspective) and Moderators (Gender, Family Network Acceptance)

Examining the interaction between gender and SSBS with the bootstrap method showed a significant moderation effect: $\mathrm{B}=0.06 ; p=0.001 ; 95 \% \mathrm{CI}(0.02 ; 0.09)$. Statistics for interaction model: $\mathrm{F}_{(2354)}=16.97 ; p<0.001 ; \mathrm{R}^{2}$ change $=0.03$. The interaction effects between (1) DBTP and gender, (2) family network acceptance and DBPT, and (3) family network acceptance and SSBS were insignificant (see Table 4).

Table 4. Depression as an effect of the interaction between the moderators (gender, family network acceptance) and the independent variables (DPTB, student burnout).

\begin{tabular}{|c|c|c|c|c|c|c|}
\hline \multirow{3}{*}{ Variables } & \multicolumn{6}{|c|}{ Outcome } \\
\hline & \multirow{2}{*}{ Coefficient } & \multirow{2}{*}{$S E$} & \multirow{2}{*}{$t$} & \multirow{2}{*}{$p$} & \multicolumn{2}{|c|}{$95 \% C I$} \\
\hline & & & & & $L L$ & $U L$ \\
\hline Gender & 0.16 & 0.20 & 3.46 & 0.001 & 0.39 & 1.07 \\
\hline DBTP & 0.48 & 0.30 & 9.79 & $<0.001$ & 2.37 & 3.56 \\
\hline DBTP $\times$ Gender & 0.01 & 0.30 & 0.17 & 0.869 & -0.55 & 0.65 \\
\hline Model Summary & \multicolumn{6}{|c|}{$\begin{array}{c}F_{(3351)}=39.83 ; p<0.001 ; R=0.50 ; R^{2}=0.25 ; \Delta R^{2}=0.25 \\
R^{2} \text { change }=0.00\end{array}$} \\
\hline Bootstrap method & 0.05 & & & 0.869 & -0.51 & 0.68 \\
\hline Gender & 0.16 & 0.43 & 3.11 & 0.002 & 0.49 & 2.17 \\
\hline SSBS & 0.23 & 0.02 & 4.45 & $<0.001$ & 0.04 & 0.11 \\
\hline SSBS $\times$ Gender & 0.18 & 0.02 & 3.50 & 0.001 & 0.03 & 0.09 \\
\hline Model Summary & \multicolumn{6}{|c|}{$\begin{array}{c}F_{(2352)}=16.97 ; p<0.001 ; R=0.36 ; R^{2}=0.13 ; \Delta R^{2}=0.11 ; \\
R^{2} \text { change }=0.03\end{array}$} \\
\hline Bootstrap method & 0.06 & & & 0.001 & 0.02 & 0.09 \\
\hline Family network acceptance & -0.17 & 0.20 & -3.46 & 0.001 & -1.09 & -0.30 \\
\hline DBTP & 0.43 & 0.30 & 9.02 & $<0.001$ & 2.10 & 3.27 \\
\hline DBTP $\times$ Family network acceptance & 0.01 & 0.30 & 0.22 & 0.828 & -0.52 & 0.65 \\
\hline Model Summary & \multicolumn{6}{|c|}{$\begin{array}{c}F_{(2352)}=39.80 ; p=<0.001 ; R=0.0 .50 ; R^{2}=0.25 ; \Delta R^{2}=0.25 ; R^{2} \text { change }= \\
0.00\end{array}$} \\
\hline Bootstrap method & 0.07 & & & 0.807 & -0.45 & 0.60 \\
\hline Family network acceptance & -0.25 & 0.21 & -4.92 & $<0.001$ & -1.45 & -0.62 \\
\hline SSBS & 0.21 & 0.02 & 4.21 & $<0.001$ & 0.04 & 0.10 \\
\hline SSBS $\times$ Family network acceptance & 0.10 & 0.02 & 2.01 & 0.045 & 0.001 & 0.07 \\
\hline Model Summary & \multicolumn{6}{|c|}{$\begin{aligned} F_{(2352)}=18.93 ; p=<0.001 ; R=0.37 ; R^{2}=0.14 ; \Delta R^{2}=0.13 & ; \\
& R^{2} \text { change }=0.01\end{aligned}$} \\
\hline Bootstrap method & 0.03 & & & 0.067 & -0.001 & 0.07 \\
\hline
\end{tabular}

Note: DBTP—Deviation from balanced time perspective; SSBS—Student school burnout; SE—-standard error; $t$ - $t$ statistic; $p$-significance; $95 \% \mathrm{CI}-95 \%$ Confidence intervals; $L L$-lower limit; $U L$-upper limit; $R^{2}-R$-squared; $\Delta R^{2}$-adjusted $R$-squared. 
3.4. Simple Mediation Effect of DBPT on the Association between Student Burnout and Depression (Model 1)

The findings confirmed significant direct effects of student burnout on depression (path c, see Table 5) and of student burnout on DBPT (path a, see Table 5). DBPT (mediator) also directly impacted the depression dependent variable (path $b$, see Table 5). However, the mediator reduced the student burnout impact on depression to an insignificant level when both variables were tested together (path $\mathrm{c}^{\prime}$, see Table 5 and Figure 2).

Table 5. Simple mediation analysis (Model 1).

\begin{tabular}{|c|c|c|c|c|c|c|c|c|}
\hline \multirow{2}{*}{ Effect } & \multirow{2}{*}{ Path } & \multirow{2}{*}{ Unstandardized Effects } & \multirow{2}{*}{$S E$} & \multirow{2}{*}{ Standardized Effects } & \multirow{2}{*}{$t$} & \multirow{2}{*}{$p$} & \multicolumn{2}{|c|}{$95 \% C I$} \\
\hline & & & & & & & $L L$ & $U L$ \\
\hline \multirow{4}{*}{ Direct effects } & $\mathrm{SSBS} \rightarrow \mathrm{DEP}(\mathrm{c})$ & 0.09 & 0.02 & 0.27 & 5.21 & $<0.001$ & 0.05 & 0.50 \\
\hline & $\mathrm{SSBS} \rightarrow \mathrm{DEP}\left(\mathrm{c}^{\prime}\right)$ & 0.03 & 0.02 & 0.10 & 1.93 & 0.054 & -0.001 & 0.06 \\
\hline & SSBS $\rightarrow$ DBTP & 0.02 & 0.003 & 0.39 & 7.84 & $<0.001$ & 0.02 & 0.03 \\
\hline & $\mathrm{DBTP} \rightarrow \mathrm{DEP}$ & 2.73 & 0.31 & 0.44 & 8.72 & $<0.001$ & 2.11 & 3.35 \\
\hline Indirect effect & $\mathrm{SSBS} \rightarrow \mathrm{DBTP} \rightarrow \mathrm{DEP}$ & 0.05 & 0.01 & 0.17 & & & 0.012 & 0.23 \\
\hline
\end{tabular}

Note: DBTP—Deviation from balanced time perspective; SSBS—Student school burnout; DEP—depression; SE—-standard error; $t$ — $t$ statistic; $p$ —significance; $95 \%$ CI—95\% Confidence intervals; $L L$-lower limit; $U L$ - upper limit.

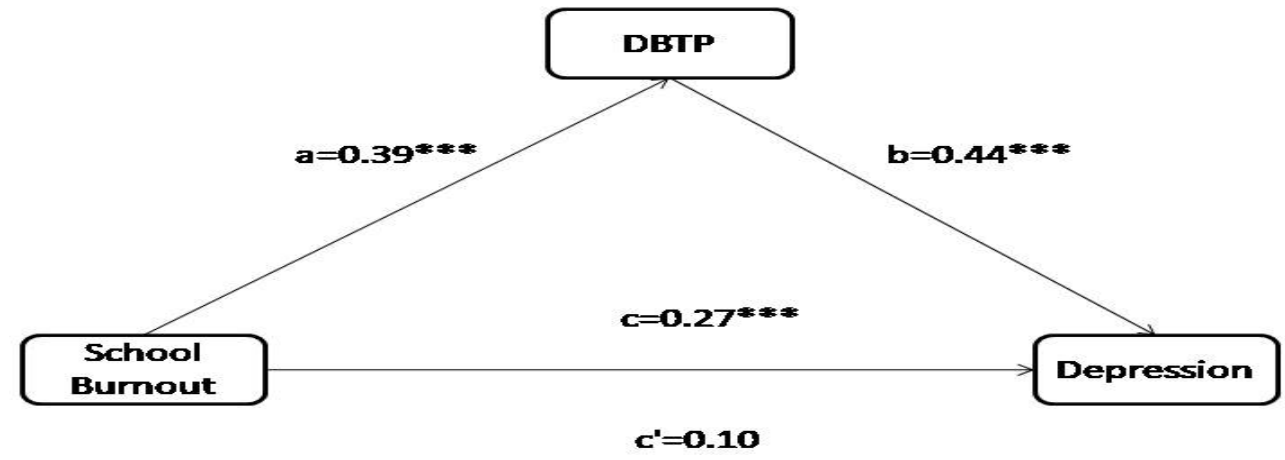

Figure 2. Simple mediation effect of DBPT on the relationship between school burnout and depression. Note: ${ }^{* * *} p<0.001$.

\subsection{The Moderation-Mediation Analysis (Model 2)}

The results revealed that the two interaction effects of (1) DBPT and gender and (2) DBPT and family network acceptance on depression were insignificant $(\mathrm{B}=-0.35 ; 95 \%$ $\mathrm{CI}(-0.96 ; 0.26), \mathrm{B}=-0.21 ; 95 \% \mathrm{CI}(-0.82 ; 0.39)$, respectively). However, the interaction effects of student burnout (SSBS) and gender, as well as of student burnout and family network acceptance on depression were significant $(\mathrm{B}=0.05 ; 95 \% \mathrm{CI}(0.02 ; 0.08), \mathrm{B}=0.04$; $95 \% \mathrm{CI}(0.01 ; 0.07)$, respectively). According to the results, school burnout also indirectly impacted depression via DBPT $(\mathrm{B}=0.06 ; 95 \% \mathrm{CI}(0.03 ; 0.10))$ (see Table 6 and Figure 3 ).

The findings revealed that gender and family network acceptance impact the relation between student burnout and depression. Specifically, the relation between student burnout and depression in the girls group with low family network acceptance was positive, while in the boys sample with low family network acceptance, this relation was negative. Moreover, it seems that in the girls sample, regardless of family network acceptance, student burnout increases in direct proportion to depression; in the boys subgroup, the direction of the relationship between variables differs depending on the level of family network acceptance: in the boys sample with high family network acceptance, the level of depression is constant despite increasing burnout; in the boys group with low family network acceptance, depression decreases as student burnout rises (see Figure 4). 
Table 6. Significance of moderation-mediation effects by bootstrapping (Model 2).

\begin{tabular}{|c|c|c|c|c|c|}
\hline & \multirow{2}{*}{ Path } & \multirow{2}{*}{ Unstandardized Indirect Effects } & \multirow{2}{*}{$S E$} & \multicolumn{2}{|c|}{$95 \% C I$} \\
\hline & & & & $L L$ & $U L$ \\
\hline \multirow{5}{*}{ Direct effects } & $\mathrm{SSBS} \rightarrow \mathrm{DEP}$ & 0.03 & 0.02 & -0.004 & 0.06 \\
\hline & $\mathrm{SSBS} \rightarrow \mathrm{DBTP}$ & 0.02 & 0.003 & 0.02 & 0.03 \\
\hline & $\mathrm{DBTP} \rightarrow \mathrm{DEP}$ & 2.43 & 0.31 & 1.82 & 3.04 \\
\hline & Gender $\rightarrow$ DEP & 0.72 & 0.19 & 0.34 & 1.09 \\
\hline & $\begin{array}{l}\text { Family network } \\
\text { acceptance } \rightarrow \text { DEP }\end{array}$ & -0.74 & 0.19 & -1.13 & -0.36 \\
\hline \multirow{4}{*}{ Interaction effects } & SSBS and Gender $\rightarrow$ DEP & 0.05 & 0.02 & 0.02 & 0.08 \\
\hline & $\begin{array}{l}\text { SSBS and Family network } \\
\text { acceptance } \rightarrow \text { DEP }\end{array}$ & 0.04 & 0.02 & 0.01 & 0.07 \\
\hline & DBTP and Gender $\rightarrow$ DEP & -0.35 & 0.31 & -0.96 & 0.26 \\
\hline & $\begin{array}{c}\text { DBTP and Family network } \\
\text { acceptance } \rightarrow \text { DEP }\end{array}$ & -0.21 & 0.31 & -0.82 & 0.39 \\
\hline Indirect effect & $\mathrm{SSBS} \rightarrow \mathrm{DBPT} \rightarrow \mathrm{DEP}$ & 0.06 & 0.02 & 0.03 & 0.10 \\
\hline
\end{tabular}

Note: DBTP-Deviation from balanced time perspective; SSBS-Student school burnout; DEP-depression SE—standard error; $95 \%$ CI—95\% Confidence intervals; $L L$-lower limit; $U L$-upper limit.

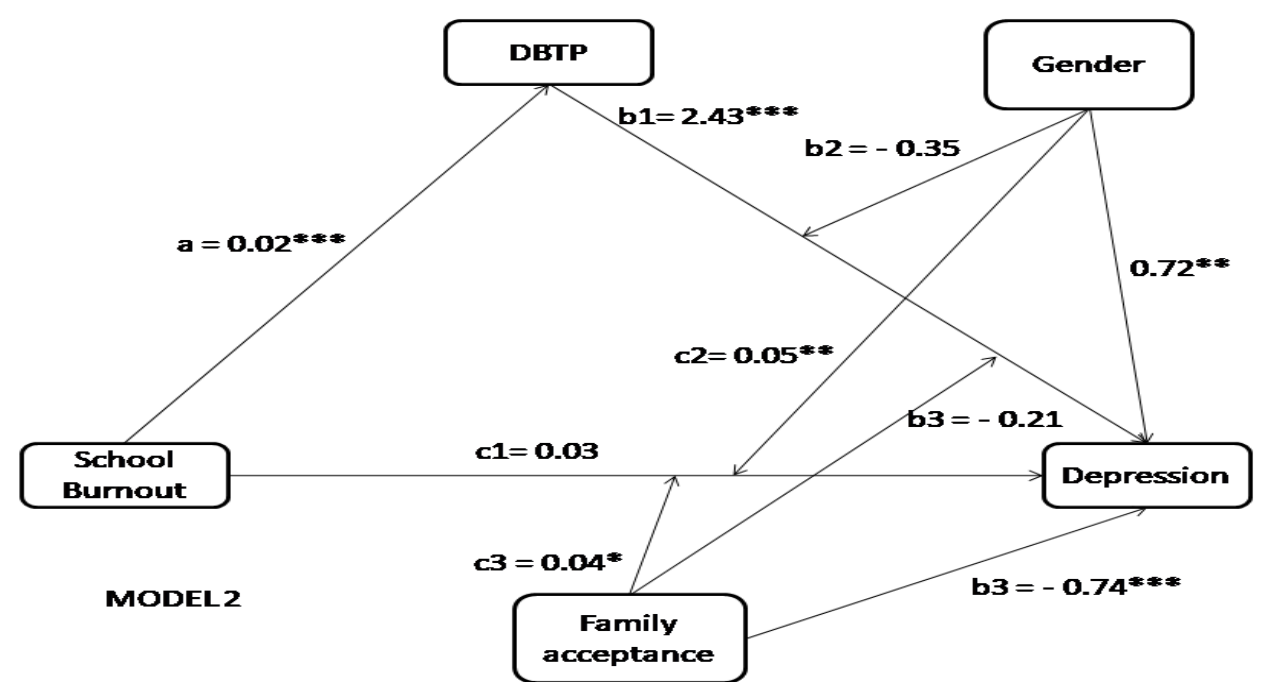

Figure 3. Graphical visualization of the moderation-mediation effect. Note: ${ }^{*} p<0.05 ;{ }^{* *} p<0.01$; *** $p<0.001$.

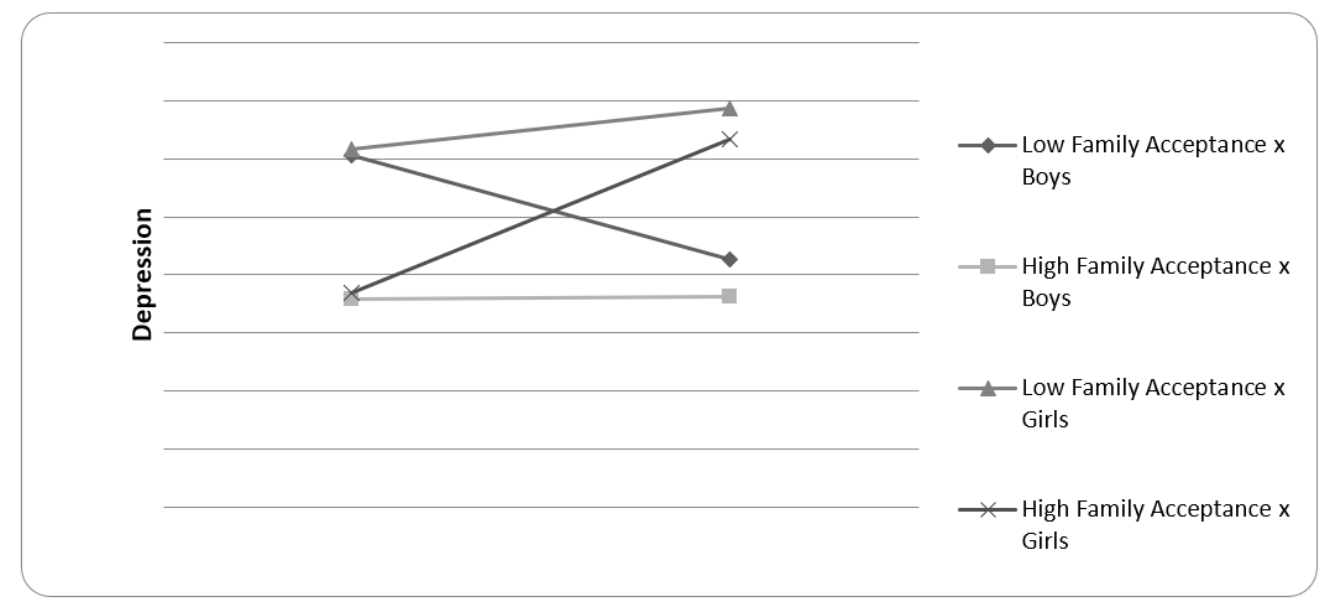

Figure 4. Relationship between depression and burnout for the two mediators' interactions. 


\section{Discussion}

The normative (balanced) pattern of time perspective is recognized as an important individual characteristic and is associated with optimal well-being [16]. The importance of the balanced time perspective (BTP) has also been confirmed for school functioning and outcomes such as education aspiration, learning motivation, and engagement [36]. School burnout and loss of interest in school activities during adolescence are often related to low academic performance and to students' experience of intense stress related to fulfilling academic duties, the intensity of which increases with each subsequent level of education [28]. Chronic educational stress can lead to emotional exhaustion, cynicism about school (a detached attitude and loss of interest), and a sense of inadequacy as a student [28], all of which have many negative short- and long-term psychosocial consequences, such as depression. Depression negatively affects school functioning by reducing cognitive functioning, significantly contributing to poorer academic performance and a decline in activity [2]. Adolescents suffering from burnout are usually more exposed to depressive disorders, which lead to poor academic achievement, difficulties at school, and behavioral problems. Previous studies provide strong evidence for the influence of students' mental representation of their academic future on their present classroom behaviors, motivations, and decisions [37]. School burnout becomes more prevalent in adolescents and teachers and is associated with social support [38]. According to Zimbardo and Boyd [13,14], futureoriented individuals can plan ahead, predict future problems, and defer gratification to accomplish long-term goals. On the contrary, the unbalanced time perspective is associated with lower self-control and mental/behavioral problems, including all three core burnout symptoms: exhaustion, cynicism, and lower personal accomplishment [30,31]. Based on the above-mentioned empirical results, the primary aim of the current study was to examine the mediating effect of deviation from the balanced time perspective (DBTP) on the relationship between student burnout (SSBS) and adolescent depression (DEP) due to the fact that unbalanced time perspective was found to be a risk factor for mental health problems such as depressive symptoms, negative affect, and alcohol use [31,39,40]. The results provide strong support for the notion that greater SSBS may influence DEP via DBPT. Our findings are in line with results showing that the balanced time perspective (or a lack thereof, namely, DBTP) plays a moderating role between different individual characteristics (personality and temperamental traits, executive functioning) and mental health outcomes or risky behaviors [41-43]. Basically, our findings show that school burnout impairs students' adaptation mechanisms related to the balanced time perspective (BTP). A lack of flexibility in switching between past, present, and future TP as well as a strong tendency to focus on negative life experiences make such students more prone to developing depressive symptoms. It is worth recalling the recently proposed definition of burnout in the BAT model by Schaufeli and Taris: "burnout is the combination of the inability and the unwillingness to no longer spend the necessary effort ( . . ) for proper task completion" ([44], p. 3) and is characterized by primary dimensions (e.g., exhaustion, emotional and cognitive impairment, mental distance) and secondary dimensions (e.g., depressed mood, psychological distress, and psychosomatic complaints). It seems that the reduced functional capacity to adequately regulate one's psychological states and behaviors also refers to time orientation. The mental inability to regulate particular time horizons related to strong negative past perspective and weak future perspective appears to engender a stronger intention to disengage from health-protective behaviors; in turn, this may drive more inconsistent reactions that are related to psychological distress and depression. On this basis, it was assumed that the unbalanced time perspective indicates a lack of effective behavioral strategies and leads to maladjustment to the school environment. On the other hand, the balanced time perspective might be a preventive factor regarding the risk of mental disorders in adolescents; it is also an important factor in the prevention of school burnout, improving well-being and optimal functioning $[45,46]$, and better academic performance [47]. 
The present study also aimed to test the role of gender and family network acceptance as moderators of the relationship between burnout and depression. The results show that girls were more depressed than boys overall; this is quite a normative outcome compared with a meta-analysis of empirical studies results from over 90 different countries, which showed that depressive symptoms in women are significantly more frequent than in men; gender differences were found to emerge in early development at the age of 12 and increase in adolescence [47]. Our study gave similar results to those of Slivar [48] in a Slovenian sample, who showed that school burnout is related to poor family relationships. Family network acceptance and support are significant factors that promote well-being and protection against the risks of mental problems and maladaptive behaviors in youth. The study found that students with low family network acceptance suffered from a higher level of all three dysfunctional variables (depression, school burnout, and unbalanced time perspective) than students with high family network acceptance. However, the findings also demonstrated that the greater the SSBS, the greater the DBPT, regardless of gender and level of family network acceptance. Unexpectedly, higher SSBS was positively associated with higher DEP, but not in the low family network acceptance sample. A positive association between DBPT and DEP was not found in the boys sample. Moreover, it was confirmed that gender and family network acceptance play an important role as moderators in the association between SSBS and DEP; such an interaction was not found for DBPT. Furthermore, considering both moderators (gender and family network acceptance), the relationship between student burnout and depression in the girls group with low family network acceptance is positive, while it is negative in the boys sample with low family network acceptance. In general, the mediation effect is more complicated than expected and, regardless of the two assumed factors (family network acceptance and gender), the time perspective also seems to be a significant moderator. Our results are consistent with the gender differences in TP found by Bodecka and colleagues [49], who showed that the hedonistic time perspective (PH) in the women's subgroup was negatively correlated with psychological distress; however, this correlation was positive in the men's subgroup. Moreover, gender moderated the relationship between the present hedonistic TP and depressiveness: higher PH was associated with fewer depressive symptoms among women. An inverse relationship was found in the men's sample: men scoring higher on PH displayed more depressive symptoms. In light of our findings, temporal dysregulation seems to be responsible for (or related to) the inability to effectively adjust the level of one's own activity to educational tasks, to cope with school-related problems, or to manage personal resources. Past research suggested that TP plays a key role in students disengaging from short-term, goal-oriented behaviors, thus resulting in worse grades in the long term [46]. Similarly, the presented findings show that students with a more unbalanced time perspective tend to be unable to meet school demands and cope with stress effectively, making them suffer from chronic fatigue or school burnout and depressiveness in the long term.

Several limitations necessitate a degree of care when interpreting these findings. The sample consisted only of adolescents from the third grade of secondary school; therefore, the age range is strictly limited. The participants were not a clinical group with depression disorder but they participated in regular school activities as part of preparation for their matrix exam. It should also be emphasized that depressive symptoms may differ depending on gender, but this aspect was not controlled. The study was cross-sectional; therefore, it is impossible to form causality statements about the links between variables. It is advisable to continue searching for other indicators of adolescent depression and burnout, such as psychological states (e.g., feelings of loneliness, student alienation, or perceived social support from peers and teachers) and academic behavior and outcomes (e.g., attending tutoring or additional lessons, boredom at school, time spent on learning). As such, future research is necessary to gain a greater understanding on how an unbalanced time perspective can impact a student's mental health. 


\section{Conclusions}

Deviation from the balanced time perspective increases the risk of adolescent depressiveness; it is through this individual characteristic that burnout can lead to depression. Given that the cognitive ability to effectively change time perspectives is based on the regularities of learning processes, professionals (school psychologists and counsellors) should implement time-perspective development training for adolescents to prevent the development of mental health problems and school burnout. Improving adaptive time perspectives and balancing them will ensure high school-related well-being and reduce potential psychological distress associated with school performance. Our findings suggest that the ways in which adolescent boys and girls balance time horizons differ. As such, different intervention strategies may be necessary depending on the individual's gender.

Author Contributions: Conceptualization, E.M. and J.K.; Data curation, E.M.; Methodology, E.M. and J.K; Formal analysis, E.M. and K.T. and J.K.; Investigation, E.M.; Statistics, K.T.; Writing-original draft preparation, E.M. and K.T. and J.K.; Writing-review and editing, K.T. and J.K.; Visualization, K.T.; Supervision, J.K.; Project administration, E.M. All authors have read and agreed to the published version of the manuscript.

Funding: This research received no external funding.

Institutional Review Board Statement: The study was conducted according to the guidelines of the Declaration of Helsinki, and approved by the Ethics Committee) of Institute of Psychology, Pedagogical University (protocol approved 23 May 2019).

Informed Consent Statement: Informed consent was obtained from all subjects involved in the study.

Data Availability Statement: The data presented in this study are available on request from the corresponding author. The data are not publicly available at the participants' requests.

Conflicts of Interest: The authors declare no conflict of interest.

\section{References}

1. Keyes, K.M.; Gary, D.; O’Malley, P.M.; Hamilton, A.; Schulenberg, J. Recent increases in depressive symptoms among US adolescents: Trends from 1991 to 2018. Soc. Psychiatry Psychiatr. Epidemiol. 2019, 54, 987-996. [CrossRef] [PubMed]

2. Dudek, M. Depresja wśród młodzieży licealnej (Depression among high-school students). Rocz. Kom. Nauk Pedagog. 2014, 67, 139-151. Available online: https://journals.pan.pl/dlibra/publication/95219/edition/82113/content (accessed on 1 February 2022).

3. Jacobs, S.R.; Dodd, D.K. Student Burnout as a Function of Personality, Social Support, and Workload. J. Coll. Stud. Dev. 2003, 44, 291-303. [CrossRef]

4. Freudenberger, H.J. Staff Burn-Out. J. Soc. Issues 1974, 30, 159-165. [CrossRef]

5. Maslach, C.H.; Jackson, S.; Leiter, M. The Maslach Burnout Inventory Manual. In Evaluating Stress: A Book of Resources; Zalaquett, C.P., Wood, R.J., Eds.; The Scarecrow Press: Lanham, MD, USA, 1997.

6. Kiuru, N.; Aunola, K.; Nurmi, J.-E.; Leskinen, E.; Salmela-Aro, K. Peer group influence and selection in adolescents' school burnout: A longitudinal study. Merrill-Palmer Q. 2008, 54, 23-55. [CrossRef]

7. Salmela-Aro, K.; Vuori, J.; Koivisto, P. Adolescents' motivational orientations, school-subject values, and well-being: A personcentered approach. Hell. J. Psychol. 2007, 4, 310-330.

8. Tuominen, H.; Salmela-Aro, K.; Niemivirta, M. Achievement goal orientations and subjective well-being: A person-centred analysis. Learn. Instr. 2008, 18, 251-266. [CrossRef]

9. Aypay, A.; Sever, M. School as if a workplace: Exploring burnout among high school students/Bir iş yeri gibi okul: Lise öğrencileri arasında tükenmişliğin keşfi. Eğitimde Kuram Uygul. 2015, 11, 460-472.

10. Salmela-Aro, K.; Savolainen, H.; Holopainen, L. Depressive symptoms and school burnout during adolescence: Evidence from two cross-lagged longitudinal studies. J. Youth Adolesc. 2009, 38, 1316-1327. [CrossRef]

11. Parker, P.D.; Salmela-Aro, K. Developmental processes in school burnout: A comparison of major developmental models. Learn. Individ. Differ. 2011, 21, 244-248. [CrossRef]

12. Stolarski, M.; Matthews, G.; Postek, S.; Zimbardo, P.G.; Bitner, J. How we feel is a matter of time: Relationships be tween time perspectives and mood. J. Happiness Stud. 2014, 15, 809-827. [CrossRef]

13. Zimbardo, P.G.; Boyd, J.N. Putting time in perspective: A valid, reliable individual-difference metric. J. Personal. Soc. Psychol. 1999, 77, 1271-1288. [CrossRef]

14. Zimbardo, P.G.; Boyd, J.N. The Time Paradox; Free Press: New York, NY, USA, 2008. 
15. Anagnostopoulos, F.; Griva, F. Exploring Time Perspective in Greek Young Adults: Validation of the Zimbardo Time Perspective Inventory and Relationships with Mental Health Indicators. Soc. Indic. Res. 2012, 106, 41-59. [CrossRef]

16. Stolarski, M.; Bitner, J.; Zimbardo, P.G. Time perspective, emotional in telligence and discounting of delayed awards. Time Soc. 2011, 20, 346-363. [CrossRef]

17. Zhang, J.W.; Howell, R.T. Do time perspectives predict unique variance in life satisfaction beyond personality traits? Personal. Individ. Differ. 2011, 50, 1261-1266. [CrossRef]

18. Drake, L.; Duncan, E.; Sutherland, F.; Abernethy, C.; Henry, C. Time perspective and correlates of wellbeing. Time Soc. 2008, 17, 47-61. [CrossRef]

19. Veenhoven, R. Hedonism and Happiness. J. Happiness Stud. Interdiscip. Forum Subj. Well-Being 2003, 4, 437-457. [CrossRef]

20. Disabato, D.J.; Kashdan, T.B.; Short, J.L.; Jarden, A. What Predicts Positive Life Events that Influence the Course of Depression? A Longitudinal Examination of Gratitude and Meaning in Life. Cogn. Ther. Res. 2017, 41, 444-458. [CrossRef]

21. Barnett, M.; Melugin, P.; Hernandez, J. Time Perspective, Intended Academic Engagement, and Academic Performance Curr. Psychol. 2020, 39, 761-767. [CrossRef]

22. Dollete, M.; Steese, S.; Phillips, W.; Matthews, G. Understanding girls' circle as an intervention on perceived social support, body image, self-efficacy, locus of control and self-esteem. J. Psychol. 2004, 90, 204-215.

23. Dafaalla, M.; Farah, A.; Bashir, S.; Khalil, A.; Abdulhamid, R.; Mokhtar, M.; Mahadi, M.; Omer, Z.; Suliman, A.; Elkhalifa, M.; et al. Depression, Anxiety, and Stress in Sudanese Medical Students: A Cross Sectional Study on Role of Quality of Life and Social Support. Am. J. Educ. Res. 2016, 4, 937-942. [CrossRef]

24. Bowlby, J. Attachment and Loss: 1969/1982; Basic Books: New York, NY, USA, 1969; Volume 1.

25. Friedlander, L.; Reid, G.; Shupak, N.; Cribbie, R. Social Support, Self-Esteem, and Stress as Predictors of Adjustment to University Among First-Year Undergraduates. J. Coll. Stud. Dev. 2007, 48, 259-274. [CrossRef]

26. Awang, M.; Kutty, F.; Ahmad, A. Perceived Social Support and Well Being: First-Year Student Experience in University. Int. Educ. Stud. 2014, 7, 261-270. [CrossRef]

27. Muchacka-Cymerman, A.; Tomaszek, K. Syndrom wypalenia w zawodzie nauczyciela i w roli ucznia. Przeglad literaturowy. Forum Oświatowe 2017, 29, 95-115. Available online: https://forumoswiatowe.pl/index.php/czasopismo/article/view/526 (accessed on 1 February 2022).

28. Salmela-Aro, K.; Kiuru, N.; Leskinen, E.; Nurmi, J.E. School burnout inventory (SBI) reliability and validity. Eur. J. Psychol. Assess. 2009, 25, 48-57. [CrossRef]

29. Salmela-Aro, K.; Upadyaya, K.; Hakkarainen, K.; Lonka, K.; Alho, K. The dark side of internet use: Two longitudinal studies of excessive internet use, depressive symptoms, school burnout and engagement among Finnish early and late adolescents. J. Youth Adolesc. 2017, 46, 343-357. [CrossRef]

30. Papastamatelou, J.; Unger, A. Differences in burnout proneness depend on time perspective-evidence from an occupational sample of industrial employees and MBA students. Dialogues Clin. Neurosci. Ment. Health 2018, 1, 52-57.

31. Stolarski, M.; Zajenkowski, M.; Jankowski, K.; Szymaniak, K. Deviation from the balanced time perspective: A systematic review of empirical relationships with psychological variables. Personal. Individ. Differ. 2020, 156, 109772. [CrossRef]

32. Tomaszek, K.; Muchacka-Cymerman, A. Polish Adaptation of the ESSBS School-Burnout Scale: Pilot Study Results. Hacet. Üniversitesi Ĕ̆itim Fakültesi Derg. 2019, 34, 418-433. [CrossRef]

33. Aypay, A. Elementary School Student Burnout Scale for Grades 6-8: A Study of Validity and Reliability. Educ. Sci. Theory Pract. 2011, 11, 520-527.

34. Mojs, E.; Bartkowska, W.; Kaczmarek, Ł.D.; Ziarko, M.; Bujacz, A.; Warchoł-Biedermann, K. Właściwości psychometryczne polskiej wersji skróconej Skali Depresji Kutchera dla Młodzieży (Kutcher Adolescent Depression Scale)- pomiar depresji w grupie studentów. Psychiatr. Pol. 2015, 49, 135-144. [CrossRef] [PubMed]

35. Przepiórka, A. The Determinants of Realizing Entrepreneurial Goals. Ph.D. Thesis, Katolicki Uniwersytet Lubelski Jana Pawła II Lublin, Poland, 2011, unpublished.

36. Hayes, A.F. Introduction to Mediation, Moderation, and Conditional Process Analysis; Guilford Press: New York, NY, USA, 2017.

37. Burns, E.C.; Martin, A.J.; Collie, R.J. A future time perspective of secondary school students' academic engagement and disengagement: A longitudinal investigation. J. Sch. Psychol. 2021, 84, 109-123. [CrossRef]

38. Fiorilli, C.; Albanese, O.; Gabola, P.; Pepe, A. Teachers' emotional competence and social support: Assessing the mediating role of teacher burnout. Scand. J. Educ. Res. 2017, 61, 127-138. [CrossRef]

39. Jankowski, K.S.; Zajenkowski, M.; Stolarski, M. What are the optimal levels of time perspectives? Deviation from the balanced time perspective-revisited (DBTP-r). Psychol. Belg. 2020, 60, 164-183. [CrossRef] [PubMed]

40. McKay, M.T.; Cole, J.C. Does deviation from a balanced time perspective meaningfully relate to alcohol use and symptoms of anxiety and depression? Comparing results using DBTP and DBTP-r. Curr. Psychol. 2021. [CrossRef]

41. Kruger, D.J.; Reischl, T.; Zimmerman, M.A. Time perspective as a mechanism for functional developmental adaptation. J. Soc. Evol. Cult. Psychol. 2008, 2, 1-22. [CrossRef]

42. Sobol-Kwapińska, M. Calm down-It's only neuroticism. Time perspectives as moderators and bmediators of the relationship between neuroticism and well-being. Personal. Individ. Differ. 2016, 94, 64-71. [CrossRef] 
43. Stolarski, M.; Fieulaine, N.; Zimbardo, P.G. Putting time in a wider perspective: The past, the present, and the future of time perspective theory. In The SAGE Handbook of Personality and Individual Differences; Zeigler-Hill, V., Shackelford, T., Eds.; SAGE: Thousand Oakes, CA, USA, 2018; pp. 592-628.

44. Schaufeli, W.B.; De Witte, H.; Desart, S. Manual Burnout Assessment Tool (BAT). Version 2.0; KU Leuven: Leuven, Belgium, 2020.

45. Boniwell, I.; Osin, E.; Sircova, A. Introducing time perspective coaching: A new approach to improve time management and enhance well-being. Int. J. Evid. Based Coach. Mentor. 2014, 12, 24-40.

46. Boniwell, I.; Zimbardo, P.G. Balancing time perspective in pursuit of opti mal functioning. In Positive Psychology in Practice; Linley, P.A., Joseph, S., Eds.; John Wiley \& Sons: Hoboken, NJ, USA, 2004; pp. 165-178.

47. Salk, R.H.; Hyde, J.S.; Abramson, L.Y. Gender differences in depression in representative national samples: Meta-analyses of diagnoses and symptoms. Psychol. Bull. 2017, 143, 783-822. [CrossRef]

48. Slivar, B. The syndrome of burnout, self-image, and anxiety with grammar school students. Psihol. Obz. Horiz. Psychol. 2001, 10, 21-32.

49. Bodecka, M.; Nowakowska, I.; Zajenkowska, A.; Rajchert, J.; Kaźmierczak IJelonkiewicz, I. Gender as a moderator between Present-Hedonistic time perspective and depressive symptoms or stress during COVID-19 lock-down. Personal. Individ. Differ. 2021, 168, 110395. [CrossRef] [PubMed] 